\title{
SENTIDOS DA ADOLESCÊNCIA NO CONTEXTO DO ESPORTE DE ALTO RENDIMENTO
}

\section{SENSE OF ADOLESCENCE IN THE CONTEXT OF HIGH PERFORMANCE SPORT}

\author{
Isabela Amblard ${ }^{1}$ \\ Fatima Maria Leite $\mathrm{Cruz}^{2}$
}

\section{Resumo}

Este estudo compreendeu repercussões da experiência de ser atleta do esporte de alto rendimento por adolescentes, no cotejo entre projetos de vida e expectativas sociais. $\mathrm{O}$ entendimento da adolescência pautou-se na Psicologia Sócio-histórica e o embasamento teórico-metodológico, na Teoria das Representações Sociais. Participaram da pesquisa 101 atletas adolescentes das modalidades natação e vôlei; aplicamos questionários de associação livre analisados pelo software EVOC, e entrevistas interpretadas pela análise temática. Os resultados apresentaram singularidades na vivência adolescente: a experiência de ser atleta foi positivada; a derrota objetivada na tristeza; e práticas esportivas de superação ancoram o futuro e os projetos de vida.

Palavras-chave: Desenvolvimento Humano. Adolescências. Teoria das Representações Sociais. Atleta. Esporte de alto rendimento.

\begin{abstract}
This study comprehended the experience repercussion of being high performance young athletes, in the comparison between life projects and social expectations. The understanding of adolescence was based on Social-historic Psychology and the basement theoretical-methodological basis, in the theory of social representations. A total of 101 adolescents athletes in swimming and volleyball modalities participated in this research; a questionnaire of free association was applied and analyzed by EVOC software, and the interviews interpreted by thematic analysis. The results presented singularities in the adolescent experience: the experience of being an athlete was
\end{abstract}

\footnotetext{
1 Professora Substituta da Universidade Federal de Pernambuco. Graduação em Psicologia pela Universidade Católica de Santos, Mestrado em Psicologia - UFPE (2012) . pesquisadora do do Laboratório de Interação Humana - LABINT da UFPE e Líder do Grupo de Pesquisa do Núcleo de Formação continuada didático-pedagógica de Professores da UFPE - NUFOPE. Email: isabela.amblard@gmail. com

2 Professora Associada da Universidade Federal de Pernambuco (UFPE), Professora dos Programas de Pós-Graduação em Psicologia e do Programa de Pós-graduação em Educação Matemática e Tecnológica da UFPE. Graduação em Psicologia - UFPE (1977), Mestrado em Educação - UFPE (1998) e Doutorado em Educação - UFPE (2006). Pesquisadora do Laboratório de Interação Humana - LABINT da UFPE e Líder do Grupo de Pesquisa do Núcleo de Formação continuada didático-pedagógica de Professores da UFPE - NUFOPE. E-mail: fatimacruz@yahoo.com
}

Revista de Administração Educacional, Recife, V. 1. № 2 - jul/dez. 2017 p. 106-122 
positive; defeat focused in sadness; and sports practices of overcoming anchors the future and life projects.

Key words: Human development. Adolescence. Social Representation Theory. Athelte. High performance sport.

\section{Introdução}

Este artigo apresenta resultados da pesquisa que analisou os sentidos da adolescência no contexto do esporte de alto rendimento. No recorte, aqui relatado, discutimos as repercussões dessa experiência em relação a inserção na vida adulta, no cotejo entre os projetos de vida dos adolescentes e as expectativas do meio social. A relevância dessa tematização se justifica na necessidade de aprofundar conhecimentos acerca das diferentes adolescências, vividas em contextos de desenvolvimento distintos e que, portanto, podem apresentar sentidos diversos a partir da dinâmica, dos artefatos e dos contextos envolvidos nessas experiências de desenvolvimento humano.

No caso dos atletas adolescentes na especificidade do contexto do esporte de alto rendimento, entendemos que essa prática “[...] traz consigo os propósitos de novos êxitos esportivos, a vitória sobre adversários nos mesmos códigos, e é exercido sob regras preestabelecidas pelos organismos internacionais de cada modalidade [...]" (TUBINO, 1992, p. 36), embora os atletas experimentem situações de derrota, também, com muita frequência.

Questionamos, na pesquisa, acerca das experiências e dos sentidos de adolescência e de ser atleta do alto rendimento, compartilhados nos grupos de atletas adolescentes: o que leva adolescentes a se manterem dedicados integralmente à prática esportiva, que lhes exige abdicação de outras atividades e da vida social? Assim, partimos da ideia de que tal contexto esportivo traz condições peculiares aos seus atletas ao experimentarem continuamente e por longo período vitórias/derrotas, e que estas experiências repercutem em suas vidas e/ou projetos de vida.

Adotamos uma perspectiva psicossocial para compreensão da adolescência e dos objetos sociais em pauta, circunscritos ao esporte de alto rendimento. Aderimos à teorização de que a demarcação do contexto de desenvolvimento diferencia modos de vida experimentados por adolescentes que compartilham de meios socioculturais e grupos sociais distintos, conforme indicado por Serge Moscovici na Teoria das Representações Sociais (TRS). Abordamos no texto alguns construtos teóricos da psicologia acerca das adolescências; em seguida, situamos o esporte de alto rendimento 
como contexto de desenvolvimento aos adolescentes; apresentamos o referencial teórico da TRS que fundamentou a pesquisa; e por fim, detalhamos o método, bem como os resultados referentes ao aspecto subjetivo das experiências compartilhadas pelos sujeitos no contexto esportivo do alto rendimento tecendo, ainda, considerações a respeito das implicações dessa experiência no desenvolvimento dos adolescentes atletas.

\section{Adolescências: construtos teóricos}

Optamos pela perspectiva da Psicologia Sócio-histórica para compreender as adolescências, por esta se alinhar à ideia de construção social que defendemos e que apoia o foco do desenvolvimento na base relacional da mediação com o outro. Segundo essa perspectiva, valor diferenciado e significados diversos são atribuídos à construção e à transformação dos objetos sociais, percebidos e representados a partir de olhares, experiências, que demarcam momentos históricos e culturais característicos de grupos sociais específicos (MENANDRO; TRINDADE; ALMEIDA, 2010).

Como um primeiro ponto situamos que a Psicologia do Desenvolvimento Humano nos aponta tensionamentos relativos à discussão sobre a adolescência, no questionamento da relação natureza/cultura que fomenta debates permanentes e variadas concepções, ainda atuais. A esse respeito temos que a natureza “[...] é constituída por estruturas e processos necessários, que existem em si e por si mesmos, independentemente de nós [...]" (CHAUI, 2003, p. 307), já a cultura tem origem na interpretação dos seres humanos sobre si mesmos e às relações que são construídas com a natureza, introduzindo novos sentidos às ações e aos objetos sociais. Desta feita, não compreendemos comportamentos e ações, a partir de determinações de ordem natural, apenas.

Chegar a tal conclusão, no entanto, não foi um processo simples. Segundo Ades (2007), essa discussão se inicia com os pressupostos darwinianos sobre a ótica evolucionista e, ainda hoje, é validada em diversas discussões que propõem a dicotomia entre natureza e cultura. Nesta abordagem, o ser humano perde a unicidade e se fragmenta de acordo com as perspectivas e os recortes que lhe são impostos.

Ao analisarmos a constituição histórica dos estudos sobre a adolescência, entendemos que suas raízes estão fincadas nessa relação natureza-cultura, na ação constante do homem em transformar a natureza para retirar dela a sua subsistência. A 
história e a cultura, portanto, não se desconectam, pois presentes pelos sujeitos sociais em interação.

Wallon (1942-2008) critica a psicologia individualista (ou psicologia da consciência de Piaget), que concebe o indivíduo como único, e secundariza as influências que o meio exerce e reflete sobre ele. Contrapõe-se à psicologia da situação, na ideia de sujeito construído no ambiente, e afirma que o sujeito já é considerado como tal devido à condição imposta à sua espécie, ou seja, por sua condição de sujeito biologicamente sócio cultural.

Neste debate teórico, temos que a Psicologia Clássica, durante muito tempo, trouxe ao público uma compreensão hegemônica acerca da adolescência, na qual se apresentava uma padronização de características e de comportamentos. Primeiro, a adolescência foi apresentada como uma síndrome de "anormalidades" temporárias na passagem para a vida adulta. Em seguida, analisada como uma fase universal que seria marcada por traços de rebeldia e transgressão também transitórios, mas que seriam aceitos socialmente porque justificariam os processos de autonomia posteriores a essa fase de oposição às regras predominantes que foram convencionadas no âmbito social.

A relevância científica do estudo acerca da adolescência e a experiência de ser atleta no esporte de alto rendimento nos parecem evidentes, quando se sabe que essa concepção pautada na visão de normalidade/anormalidade ainda é vigente, inclusive, na formação profissional em psicologia (LIRA; CRUZ, 2014), e cujas características de inconsequência e transitoriedade, não se coadunam ao que se percebe nas exigências e disciplinamento exigidos, por exemplo, na experiência de atletas adolescentes. Nesta abordagem do desenvolvimento como etapas lineares, trata-se de uma concepção universalizante que atribui à adolescência uma visão limitada e patologizada (OZELLA, 2003).

Tal perspectiva, além de ser disseminada em determinados setores e campos da Psicologia como ciência e profissão, também influencia a visão do senso comum e dos instrumentos midiáticos que propagam a ideia da adolescência como uma fase com características fixas, naturalmente constituintes do desenvolvimento humano, e que são apresentadas como uma concepção universal e descontextualizada. A ideia de transitoriedade, ou seja, de um período demarcado para a vivência da adolescência traz determinados marcadores sociais relacionados ao tempo de duração dessa fase que seria pré-determinado, indo do final da infância à vida adulta, portanto, um período estanque 
e considerado necessário, indispensável, a todos os sujeitos sem maiores distinções em seus aspectos fundamentais (MENANDRO; TRINDADE; ALMEIDA, 2010).

Em contribuição mais recente aos estudos do desenvolvimento humano, a perspectiva sócio-histórica analisa a adolescência, a partir dos contextos locais e diversos, conforme demonstram os estudos de Bock, Furtado e Teixeira (2001), Aléssio e Santos (2005), Lira e Cruz (2014), Lacerda e Cruz (2015), Amblard e Cruz (2013, 2015), nos quais os adolescentes de distintos contextos são apresentados com autonomia e com diversas modulações no desenvolvimento pessoal, esportivo e/ou profissional. Observamos, portanto, que os sentidos atribuídos à adolescência variam de acordo com os contextos socioculturais nos quais os sujeitos interagem, por isso o uso do termo adolescências, cuja pluralidade nos indica que não haveria uma experiência universal na forma de vivê-la, mas uma diversidade e multiplicidade de possibilidades, a depender do contexto de desenvolvimento, conforme reforçado por Ozella (2003).

Os estudos a respeito das concepções de juventude também compreendem que a condição juvenil é circunscrita por marcadores da cultura local, como verificado por Alves (2013) quando na análise das influências da cultura de migração na vida de uma comunidade rural que tem como principal característica o transnacionalismo. Para Pais (2011), as culturas de grupo sinalizam sua relevância nos ciganos e nas tribos urbanas, com variados grupos e denominações, rave, punk e funk, skaters e grafiters. Nessa lógica de especificidade social, cultural e histórica, Silva e Menezes (2014) propõem como exemplo a análise das mulheres quilombolas jovens, residentes na área rural de Castainho e Estivas, comunidades localizadas em Garanhuns/PE, e suas especificidades permeadas por um contexto demarcado por desigualdades e uma extrema cultura sexista.

Essas pesquisas explicitam a existência de mais de uma adolescência/juventude, afiliando-se à perspectiva sócio-histórica que compreende as diversas adolescências como construções permeadas pelas relações sociais, contextualizadas de forma histórica e cultural, em contextos distintos: grupos esportivos, de comunidades rurais, urbanas e de tantas outras ramificações, contextos e expressões.

Diversos autores corroboram com essa visão e a Psicologia Sócio-histórica, portanto, compreende a adolescência:

[...] não desenvolvimentista, pois cada sujeito o vivenciará de uma maneira, dependendo de suas interações sociais, do desenvolvimento de seus interesses, de suas necessidades e da significação que as 
mudanças biológicas têm ou tiveram (FONSECA; OZELLA, 2010, p. 413).

Especificidades históricas e culturais de diferentes grupos sociais sinalizam como esse período é percebido e representado, o que significa dizer que a ideia de adolescência é uma construção social (MENANDRO; TRINDADE; ALMEIDA, 2010). Ozella e Aguiar (2008) abordam a adolescência como um momento histórico, interpretado e construído pelos sujeitos nos quais mantêm com a sociedade uma relação de mediação constituída mutuamente, e com suas identidades preservadas.

$\mathrm{Na}$ história da humanidade, muitos foram os ritos de passagem da vida infantil para a vida juvenil e/ou adulta, geralmente associados à virilidade e força física para os rapazes e, na sociedade competitiva e do conhecimento da atualidade, os adolescentes experimentam alguns rituais de passagem com intensa pressão social. Podemos citar, por exemplo, o concurso de acesso à educação superior como uma exigência que passou a ser integrada aos projetos de vida, passaporte para o mundo do trabalho, e símbolo de prestígio social. Por vezes, a preocupação das famílias se concentra no rendimento escolar do adolescente com vistas a esse acesso à vida universitária, pois a escolarização ainda é fonte de mobilidade social.

No que se refere a estas pressões sociais, no esporte de alto rendimento, por sua vez, os atletas adolescentes cumprem com um extenuante calendário de competições, com intervalo mínimo de três meses entre os eventos esportivos, e a pressão exercida sobre eles/elas parece ser ainda maior, pois nos campeonatos o resultado deve ser imediato, o que exige superação, continuamente.

\section{A Teoria das Representações Sociais e o desempenho esportivo}

O referencial teórico-metodológico da TRS (MOSCOVICI, 2009) permite uma compreensão e explicação aprofundada dos fenômenos sociais. A TRS contribuiu com uma nova perspectiva de análise da realidade social diante da necessidade dos pesquisadores em romper com a ausência de demarcação histórica predominante nos estudos em Psicologia Social daquela época. A proposta de Moscovici foi de desnaturalização dos objetos sociais, haja vista a sua ênfase à dimensão de construção humana, histórica e cultural (ALMEIDA; SANTOS; TRINDADE, 2011).

Segundo Alba (2011), a adoção desta teoria possibilita uma abordagem dos fenômenos psicossociais em seu contexto social e histórico; permite o embasamento teórico-metodológico, que dá conta da complexidade do fenômeno estudado; possibilita 
a compreensão do sujeito como ator social, que constrói ativamente a sua realidade a partir do contexto sociocultural; favorece a uma análise circunstanciada dos processos psicossociais, através do dinamismo das representações sociais (RS). Assim, os aspectos sociais, econômicos, políticos e culturais têm relevância na dimensão e na repercussão que as práticas esportivas tomaram e continuam a tomar na vida dos adolescentes, agem, portanto, como circunscritores de seu desenvolvimento.

Em especial, o foco dessa pesquisa remete à experiência de ser atleta no esporte de alto rendimento, experiência marcada por condições de vitória/derrota que corroboram o sentido meritocrático difundido na sociedade. Há, portanto, uma ressignificação dos sentidos de acordo com as influências dos diferentes contextos, sinalizando o caráter heterogêneo das RS na medida em que se mostram distintas aos membros da sociedade (AMBLARD, 2012).

Cruz (2006) se refere à TRS como reveladora da dinâmica do real, na medida em que permite a reflexão a respeito dos objetos sociais diretamente relacionados à interação e à vida social dos sujeitos. Não há, portanto, como conceber os objetos sociais sem interação, ou seja: os objetos sociais apresentam um sentido muito mais amplo do que simples imagens desprovidas de função e representadas por uma dinâmica reprodutivista e passiva da realidade.

As RS referem-se a um conjunto de crenças, pensamentos, opiniões e ideais, denominado senso comum, que nos permite fazer referências a dado objeto. Elas se constituem em pontos de encontro do psicológico com o social, pois é a partir das experiências, dos conhecimentos, das informações e dos modelos de pensamentos transmitidos no dia a dia, por meio da tradição, educação e comunicação social, que elas se organizam. As RS são, assim, geradas nos processos comunicativos cotidianos, e expressas pela linguagem, o que as torna resultantes da interação social que envolve um processo de adesão e participação na dinâmica social.

A objetivação e a ancoragem são processos de construção das RS e visam familiarizar os sujeitos com os objetos novos com os quais precisam lidar, mantendo-os coerentes ou aproximando-os da realidade social que já lhes é familiar. Deste modo, a objetivação concretiza em significados do senso comum as abstrações, que até então pareciam sem sentido (TRINDADE; SANTOS; ALMEIDA, 2011). A ancoragem, por sua vez, “[...] transforma algo estranho e perturbador, que nos intriga, em nosso sistema particular de categorias e o compara com um paradigma de uma categoria que nós 
pensamos ser apropriada" (MOSCOVICI, 2009, p. 61), ou seja, as informações desconhecidas são ancoradas em um sistema de valores próprio dos sujeitos, os quais as denominam e classificam mediante os laços que o objeto mantém com sua inserção social.

\section{Método}

A perspectiva plurimetodológica foi adotada na pesquisa, dada a sua possibilidade de optar por variados recursos de coleta e distintos formatos de análise de dados. Nesta perspectiva, a fase empírica foi dividida em duas etapas, com o aprofundamento e o refinamento progressivo das informações que foram analisadas e devolvidas aos participantes na etapa seguinte (CRUZ, 2006).

A escolha das modalidades esportivas, natação e vôlei, como campo da pesquisa teve como critério a prática de um esporte individual e outro coletivo, ambos considerados pelas confederações esportivas como esportes em ascensão social, com visibilidade perante a mídia e o público, e com algumas semelhanças nas conquistas brasileiras de títulos, tais como em campeonatos mundiais, olímpicos, e cujos atletas dessas modalidades são reconhecidos como ídolos.

Na primeira etapa da pesquisa, levantamos o campo semântico das representações sociais de vitória e de derrota, com a aplicação dos questionários de associação livre de palavras. Participaram 101 atletas, dos sexos feminino e masculino, sendo 44 da natação e 57 do vôlei, com faixa etária entre 12 e 18 anos de idade, escolhidos aleatoriamente do grupo de atletas federados nas respectivas categorias na cidade de Recife. Na segunda etapa, realizamos entrevistas individuais e foram selecionados, por sorteio, cinco atletas. Nesta etapa dividimos os participantes por modalidade esportiva e sexo, para que, ao final da seleção, tivéssemos um representante de cada modalidade e sexo, apresentados na Tabela $1^{3}$.

Tabela 1: Perfil dos atletas participantes das entrevistas

\begin{tabular}{|c|c|c|c|}
\hline Código de identificação & Modalidade & Sexo & Idade \\
\hline SNF & Natação & Feminino & 14 anos \\
\hline SNM 1 & Natação & Masculino & 13 anos \\
\hline SNM 2 & Natação & Masculino & 14 anos \\
\hline SVF & Vôlei & Feminino & 16 anos \\
\hline SVM & Vôlei & Masculino & 17 anos \\
\hline
\end{tabular}

${ }^{3}$ Codificação - letra S sujeito, seguida pela letra inicial da modalidade do esporte. $\mathrm{N}$ para natação e V, vôlei; M para masculino e F para feminino. Numeração atribuída.

Revista de Administração Educacional, Recife, V. 1. № 2 - jul/dez. 2017 p. 106-122 
Na primeira etapa, os participantes responderam às questões do Questionário de Associação Livre (QAL), constituído por seis expressões indutoras: vitória; vitória nas competições; vitória para os pais; derrota; derrota nas competições; derrota para os pais. Os sujeitos escreveram as cinco palavras que associavam quando liam cada expressão indutora.

$\mathrm{Na}$ análise dos QAL, as palavras foram quantificadas e classificadas por categorias temáticas, de acordo com a similitude semântica. As palavras com os sentidos mais recorrentes de cada categoria subsidiaram o roteiro das entrevistas individuais da segunda etapa, e cada palavra mais recorrente foi exposta aos participantes na situação de entrevista, em cartelas. No caso das associações à vitória tivemos como representantes das categorias temáticas: alegria, esforço, garra, conquista, superação, orgulho, medalha, treino, união, competição; já as categorias referentes à derrota foram: tristeza, superação, raiva, aprendizado, falta de concentração, decepção, fracasso, nova tentativa. Com esse estímulo, solicitamos aos sujeitos que explicassem os motivos que acreditavam terem sido adotados pelos atletas em suas escolhas. Na análise das entrevistas, adotamos a técnica de análise temática de conteúdo de Bardin (2004).

Neste artigo, discutiremos resultados da fase das entrevistas. Registramos, ainda, que mantivemos ao longo dos extratos que ilustram as análises, a transcrição literal das falas, respeitando a variedade linguística local e regional para o uso da língua portuguesa em situações coloquiais.

\section{Discussão dos resultados}

$\mathrm{Na}$ pesquisa, os termos indutores vitória e derrota nos permitiram a aproximação das experiências dos atletas adolescentes no esporte de alto rendimento, marcadas pelos sentidos de competitividade, pela valorização da vitória e da derrota, e a busca pela superação de seus objetivos pessoais, suas marcas e, especialmente, dos obstáculos que precisaram enfrentar. No caso da natação, compreendemos, a partir das falas dos participantes que a responsabilidade pela vitória/derrota foi colocada no sujeito em particular e na própria superação: "Pra conseguir a vitória, você tem que se superar. Pra conseguir a vitória, você tem que dar tudo o que você tem, mais do que $100 \%$ seu" (SVM). 
Interpretamos que a situação de vitória, por vezes, emergiu como sinônimo da melhoria nas marcas pessoais, portanto, o sentido é de auto superação, sem considerar a outra pessoa que compete, o adversário, como antagonista. $\mathrm{O}$ cronômetro da prova e a própria condição do atleta adolescente pareceram-nos os maiores adversários:

É tipo assim: todas as competições têm seus pontos baixos e seus pontos altos, entende? Tem seus altos e baixos e, assim, como sempre, a gente vai ter os pontos baixos também, nós temos que superar, entende? (SNM 2).

Este extrato é típico da questão da superação como um elemento construtor da vitória, pois mesmo na situação concreta de derrota houve um sentido de vitória, devido a superação pessoal. É a competição que possibilita ao adolescente este embate consigo mesmo e "se superar... você vai mostrar o que você aprendeu nos treinos, e vai mostrar seu esforço" (SNF).

$\mathrm{Na}$ prática esportiva, obviamente há o comparativo com o adversário e há o reconhecimento da vitória, quando o entrevistado faz menção ao fato do outro ter treinado e se esforçado mais do que ele e, por isso, é merecedor da vitória. Como justificativa ao mau desempenho, os atletas adolescentes também dão grande relevância à falta de concentração, como uma característica definidora de campeonatos e indica o processo de autodesenvolvimento:

Se você não tiver concentração, você não vai conseguir, principalmente no vôlei, você tem que tá... vai, para, vai para... você não pode, nunca, tirar o foco do jogo, você tem que tá sempre ligado $(\mathrm{SVM})$.

Embora em alguns relatos apareça claramente a figura do adversário como alguém que, de fato, tem a capacidade de impedir a vitória de outrem, ou seja, como uma ameaça, ficou evidente que os participantes representam a ameaça de fracasso objetivada na falta de concentração pessoal do atleta e o processo subjetivo de auto superação:

\footnotetext{
Você perde por falta de concentração, você tem que tá sempre muito concentrado, com muito foco no que você tá planejando. Se você perder o foco, você não vai conseguir alcançar aquilo que você quer e vai ter a derrota (SVM).
}

No desenvolvimento dos adolescentes, identidade e alteridade se mesclam dado o reconhecimento do sujeito a partir do outro, ao mesmo tempo em que esse outro o ameaça. Segundo Gallinkin e Zauli (2011), a identidade, constituída nas interações 
sociais, só faz sentido em contextos relacionais específicos, operando como um código de categorias que "comunica" os modos de vida, os lugares sociais dos sujeitos nas relações sociais e os valores atribuídos às pessoas e aos grupos envolvidos. Assim, o movimento em via de mão dupla ocorre nas experiências vividas por adolescentes que trazem aspectos próprios, singulares, não necessariamente vivenciados por outrem, mas que aponta também a diferenciação entre grupos. Os adolescentes, portanto, se identificam entre grupos restritos de pares, com quem podem se reconhecer mediante o compartilhamento de determinadas escolhas de estilos de vida, movimento de autoria, de fortalecimento de identidade.

No contexto relacional da trajetória esportiva, a superação é referenciada pelos atletas participantes em um sentido ainda mais amplo, ou seja, envolve valores morais, éticos e características pessoais que podem nem ter relevância para o contexto esportivo e à conquista de resultados, mas são pertinentes à sua condição de sujeito inacabado, em busca de novos aprendizados.

A necessidade de superação e de se lançarem ao futuro com esperança é explicitada através do comportamento resiliente, conforme uma atleta adolescente revelou: "Se perder, tentar se superar, tentar ser melhor ainda no próximo jogo" (SVF). Segundo Castelar-Perim (2011), um sujeito demonstra resiliência ao enfrentar não apenas uma situação adversa, mas várias, o que acaba por lhe dar certa experiência de como ultrapassar tais acontecimentos. A resiliência, portanto, não se refere ao retorno a um estado anterior, mas a superação ou adaptação diante de uma dificuldade considerada como um risco, e a possibilidade de construção de novos caminhos de vida e de um processo de subjetivação a partir do enfrentamento de situações difíceis ou conflitantes (JUNQUEIRA; DESLANDES, 2003).

Percebemos, portanto, na derrota, uma experiência como uma condição inerente ao esporte de alto rendimento, e pela alta performatividade e os escassos lugares no pódio, com frequência é mais vivenciada do que a vitória. A derrota revelou-se como uma situação muito difícil, experimentada como algo que não deu certo e, por isso, traz tristeza experimentada com ambiguidade, fragiliza e, ao mesmo tempo, é reforço para novas tentativas:

Logo depois da derrota sempre vem a desilusão, a tristeza. Às vezes vontade de desistir, tal, mas logo depois passa, tal, o que é comum né? No sentido de que você tava querendo ganhar né, no sentido de que tava com vontade. É normal, né? (SVM).

Revista de Administração Educacional, Recife, V. 1. № 2 - jul/dez. 2017 p. 106-122 
$\mathrm{O}$ aprendizado dos adolescentes se mostra nas experiências de derrota, pois a partir delas é que o atleta consegue refletir sobre a conquista de tal resultado, visando a melhoria de seus erros ou a obtenção de novas habilidades, conforme diz um outro nadador:

É porque quando você perde, você aprende, ganha mais experiência. É porque... em competição você vai pegando as manhas, é como na vitória... você vai pegando as manhas, essas coisas, pra você melhorar na outra competição... manha de concentração, da saída, essas coisas (SNM 1).

Os atletas adolescentes nos dizem que os aprendizados oriundos do contexto esportivo não ficam restritos, pois são ampliados e ganham notoriedade perante a vida e sob a forma reflexiva e focada irão aprender a lidar também com as diversas situações do cotidiano:

Quando a gente... acho que... em algum esporte, a pessoa aprende muito porque mexe com o psicológico da pessoa. E a pessoa tem que melhorar muito, tem que ter muita cabeça, tem que pensar muito, não pode ficar... os amigos se distraindo, tem que pensar só no vôlei. (SVF).

Nessa contextualização de esporte de resultados, a exigência é uma marca nos atletas adolescentes do alto rendimento, que se mostram extremamente disciplinados, comprometidos e responsáveis com suas escolhas, atitudes e comportamentos, o que desmistifica a ideia generalizada no senso comum que tipifica a adolescência como período de indisciplina e transgressão. Temos, assim, que a responsabilidade exercitada na prática esportiva aproxima os atletas adolescentes da condição da adultez. Tais aprendizados são validados e aproveitados em suas próximas experiências, especialmente quando eles vêm de uma derrota, como os próprios atletas adolescentes relatam:

Você tem que... perdeu? Levanta a cabeça e vai pra outra, vê o que tem de bom, o que tem de melhorar, o porquê você perdeu, vê os pontos fracos do seu adversário e vamo pro próximo jogo. Não pode baixar a cabeça nunca, continuar indo em frente, ver o que tem que melhorar e tal (SVM).

Assim, a partir da derrota, o atleta adolescente vive momentos difíceis, de inconformismo, com sentimentos negativados, entretanto, consegue perceber que aquela derrota é parcial, apenas um resultado de uma competição, a ser superada. É interessante perceber que, em nenhum momento, o outro como adversário apareceu nos relatos. As 
derrotas nas competições parecem ser atribuídas à responsabilidade exclusiva do sujeito que compete, ou seja, sem condicionar ao outro com quem compete.

No desenvolvimento do adolescente o perfil idealizado pelos atletas exibe rigor, classificação e seletividade. Assim, eles e elas extrapolam a situação de competição e se reconhecem como 'bons ou maus', de acordo com as suas performances, o que nos parece perverso para o sentido humano, dada as diversas possibilidades apresentadas por cada sujeito, que sente, se reconhece, e constrói a sua identidade, a despeito dessas condições de êxito/fracasso.

Refletimos, assim, acerca da transitoriedade desta prática na vida dos adolescentes, haja vista que a profissionalização, via esportes, não apareceu nos achados como um projeto de vida. Tais projetos se identificam com a continuidade da escolarização, e a relação com o sucesso não se refere diretamente às vitórias nas competições, mas à vitória na vida, na profissionalização, o que é incentivado pelos pais. Eles parecem reconhecer o valor atribuído às vitórias no esporte, ao passo que veem os estudos como uma necessidade para a inserção no mundo do trabalho:

Todos os pais falam assim: tem que se concentrar no esporte, mas também tem que se concentrar no estudo, não tá só na... os pais sempre dão apoio, a maioria dos pais sempre dão apoio, mas também sempre querem que você dê alguma coisa em troca nos estudos, porque muitos atletas não vão conseguir suceder talvez no esportivo, nem todo mundo que pratica vôlei vai se tornar um jogador de vôlei no futuro. (SVM)

No contraponto dessa situação, os atletas adolescentes, por vezes, optam por postergar a dedicação aos estudos, bem como a autonomia financeira possibilitada pelo trabalho, para viver de forma intensa a vida de atleta. Dessa maneira, se colocam tardiamente no mundo do trabalho, em busca primeiro de realizações no contexto esportivo. No trecho de entrevista, a seguir, o foco na prática da natação pareceu impedir a dedicação do atleta aos estudos, trazendo prejuízos à adaptação e aos resultados na escola:

Esse ano não, desde que eu entrei na natação... tipo, eu treino, treino, treino todo dia. Eu chego da escola de $12 \mathrm{~h}$, venho pra cá $2 \mathrm{~h}$ mais ou menos... aí chego só $9 \mathrm{~h}$ da noite, entende? Não dá aquele tempo exato pra você fazer a tarefa, estudar pra prova, não dá. É justamente por isso, não sei se por isso, mas se também porque eu não estudo... mas por isso que eu fico de recuperação (SNM 2). 
Interpretamos, por fim, que o prolongamento da vida esportiva pareceu-nos trazer ganhos no sentido subjetivo das experiências oportunizadas aos adolescentes, todavia, sem a possibilidade de conquista da independência financeira que é um marcador da vida adulta. Tal dado nos parece pertinente à realidade brasileira no que se refere ao investimento das políticas públicas nos esportes, o que gera dificuldades de planejamento ou investimento de adolescentes e jovens na carreira esportiva, e provoca nos atletas um encurtamento na vida esportiva e a decorrente busca por outras possibilidades que visem a futura inserção ao mundo do trabalho (AMBLARD; CRUZ, 2013).

\section{Considerações finais}

Este artigo enfocou aspectos de um estudo que abordou os sentidos de ser atleta, segundo atletas adolescentes do esporte de alto rendimento, nas representações sociais de vitória/derrota, e tematizou, em particular, as reflexões acerca da adolescência, nesse contexto esportivo, a partir dos resultados oriundos da etapa das entrevistas.

A adolescência se mostrou singular e diferenciada daquela teorizada como padrão por muito tempo, pela ciência da psicologia, pois os atributos de comprometimento, disciplina e responsabilidade emergiram como definidores dos atletas adolescentes no contexto da prática esportiva. Assim, a especificidade do contexto do esporte de alto rendimento significa uma das possibilidades de pensar a diversidade de adolescências, propostas por Ozella (2003): cada adolescência analisada, contextualizada e circunscrita aos marcadores sociais, culturais e históricos.

Retomamos a discussão acerca da adolescência, por ser este um fenômeno complexo, conceituado durante muito tempo pela Psicologia Clássica como sendo uma fase do desenvolvimento, transitória, prioritariamente marcada por comportamentos rebeldes e transgressores. Tais construções teóricas ainda persistem nos dias atuais, e têm grande circulação no senso comum, apresentando-se como ideias hegemônicas (OZELLA, op. cit.). No entanto, diversos estudos têm demonstrado experiências diferenciadas de desenvolvimento e suas expressões, segundo os referentes do meio sociocultural (MENANDRO; TRINDADE; ALMEIDA, 2010; AMBLARD; CRUZ, 2013, 2015).

O referencial teórico da TRS nos possibilitou analisar o pensamento social compartilhado neste grupo específico de atletas, no contexto esportivo de alto 
rendimento, e nos revelou que predomina um pensamento classificatório, competitivo, ideia disseminada no senso comum, pelos processos comunicativos. Neste contexto, o sucesso significa ser o melhor, vencer, o que é antagônico à perspectiva de uma sociedade solidária, todavia, o sentido de competitividade não emergiu entre os adolescentes, ancorado na lógica desenfreada da sociedade atual e, sim, voltada para a própria situação de auto superação.

Embora a busca por lugares de sucesso seja a tônica do esporte de alto rendimento, tal condição não pareceu repercutir negativamente nas relações sociais entre os atletas e demais pessoas ou situações do meio esportivo. Nos resultados, a vitória foi considerada uma conquista e associada à dimensão individual dos atletas e aos mecanismos que eles adotam para suportar as situações competitivas. A derrota é objetivada no sentimento de tristeza; há a auto culpabilização e auto responsabilização dos atletas pela situação, todavia, expressam que lidar com o momento negativo permite adquirir experiência o que favorece o crescimento e o aprendizado para o esporte e para a vida.

Concluímos que o contexto esportivo possibilita dificuldades relacionadas à sociabilidade pela constante rivalidade entre atletas em busca de vitórias em competições, porém, lidar com as vitórias/derrotas de modo positivo, agrega valor e aprendizado às experiências aliada à superação pessoal e, não necessariamente, ao outro, o que reflete o espírito esportivo. Isto é respeito às regras e aos adversários, bem como à aprendizagem que diferencia momentos em que o outro ora é adversário, ora é parceiro.

Observamos, ainda, que como a adolescência é entendida como transitória para os atletas, o esporte também o é e, assim, os projetos de vida são construídos com bases no investimento nos estudos, pois a profissionalização esportiva praticamente inexiste na sociedade brasileira. O tempo que os adolescentes destinam ao esporte de alto rendimento e as emoções evidenciadas ao falarem das suas rotinas esportivas, lidando com vitórias/derrotas, sugere a entrega positiva à atividade e às condições desse contexto que mobilizam aprendizagens e desenvolvimento.

\section{Referências}

ADES, C. Desde Darwin: um olhar evolucionista para a psicologia. In: DOURADO, N. M. R.; BASTOS, A. V. B. (Org.). Psicologia: novas direções no diálogo com outros campos do saber. São Paulo: Casa do Psicólogo, 2007. 
ALBA, M. Representações sociais e memória coletiva: uma releitura. In: ALMEIDA, A. M.O.; SANTOS, M. F. S.; TRINDADE, Z. A. (Org.). Teoria das representações sociais: 50 anos. Brasília: Technopolitik, 2011.p. 393-430.

ALÉSSIO, R. L. S.; SANTOS, M. F. S. Desenvolvimento humano e violência na zona rural. In: SANTOS, M. F. S. S.; ALMEIDA, L. M. (Org.). Diálogos com a teoria das representações sociais. Recife: EDUFPE/EDUFAL, 2005. p. 77-97.

AMBLARD, I. A gente anda com o bom e o mau ao lado: representações sociais de vitória/derrota segundo atletas do esporte de alto rendimento. 2012. 166f. Dissertação (Mestrado em Psicologia) - Centro de Filosofia e Ciências Humanas, Universidade Federal de Pernambuco, Recife, 2012.

AMBLARD, I.; CRUZ, F. M. L. C. Sentidos de vitória/derrota para os pais segundo atletas do alto rendimento. Psicologia: Ciência e Profissão (Online, Impresso), v. 35, p. 643-658, 2015.

Atletas adolescentes de esportes de alto rendimento e a construção de seus projetos de vida. In: COZAC, J. R. L. (Org.). Psicologia do esporte: atleta e ser humano em ação. São Paulo: Roca, 2013, p. 20-29.

ALMEIDA, A. M. O.; SANTOS, M. F. S.; TRINDADE, Z. A. Ancoragem: notas sobre consensos e dissensos. In: ALMEIDA, A. M.O.; SANTOS, M. F. S.; TRINDADE, Z.

A. (Org.). Teoria das representações sociais: 50 anos. Brasília: Technopolitik, 2011. p. 101-121.

ALVES, M. Z. Ser alguém na vida. Condição juvenil e projetos de vida de jovens moradores de um município rural da microrregião de Governador Valadares/MG. 2013. 213f. Dissertação (Mestrado em Educação) - Faculdade de Educação, Universidade Federal de Minas Gerais, Belo Horizonte, 2013.

BARDIN, L. Análise de conteúdo. 3. ed. Lisboa: Edições 70, 2004.

BOCK, A. M. B.; FURTADO, O.; TEIXEIRA, M. L. T. Psicologias: uma introdução ao estudo de psicologia. 13 ed. 3 tri. São Paulo: Saraiva, 2001.

CASTELAR-PERIM, P. Resiliência e prática desportiva: um estudo realizado com adolescentes brasileiros. 2011. 117 f. Tese (Doutorado em Ciências do Desporto). Faculdade do Desporto, Universidade do Porto, Porto, 2011.

CHAUI, M. Convite à filosofia. São Paulo: Ática, 2003.

CRUZ, F. M. L. Expressões e significados da exclusão escolar: representações sociais de professores e alunos sobre o fracasso em matemática. 2006. 363 f. Tese (Doutorado em Educação) - Centro de Educação, Universidade Federal de Pernambuco, Recife, 2006.

FONSECA, D. C.; OZELLA, S. As concepções de adolescência construídas por profissionais da estratégia em saúde da família (ESF). Interface, Botucatu, v. 14, n. 33, p. 411-424, abr/jun. 2010. Disponível em: <http://www.scielo.br/pdf/icse/v14n33/ a14v14n33.pdf>. Acesso em: 13 out. 2010.

GALINKIN, A. L.; ZAULLI, A. Identidade social e alteridade. In: TORRES, C. V.; NEIVA, E. R. (Org.). Psicologia social: principais temas e vertentes. Porto Alegre: Artmed, 2011. 
JUNQUEIRA, M. F. P. S.; DESLANDES, S. F. Resiliência e maus tratos à criança. Cadernos de Saúde Pública, Rio de Janeiro, v. 19, n. 1, p. 227-235, jan/fev. 2003. Disponível em: <http://www.scielosp.org/pdf/csp/v19n1/14923.pdf>. Acesso em: 10 out. 2011.

LACERDA, T. S.; CRUZ, F. M. L. Juventude pobre e o acolhimento institucional: os sentidos compartilhados na mídia impressa em Pernambuco. Tópicos Educacionais, v. 1, p. 250-282. 2015.

LIRA, V. T.; CRUZ, F. M. L. Juventudes pobres: sentidos construídos por psicólogos. Recife: Nova Presença, 2014.

MENANDRO, M. C. S.; TRINDADE, Z. A.; ALMEIDA, A. M. O. Gente jovem reunida: representações sociais de adolescência/juventude em textos jornalísticos. Vitória: PPGP/UFES; GM, 2010.

MOSCOVICI, S. Representações sociais: investigações em psicologia social. Editado em inglês por Gerard Duveen; traduzido do inglês por Pedrinho A. Guareschi. 6 ed. Petrópolis: Vozes, 2009.

OZELLA, S. (Org.). Adolescências construídas: a visão da psicologia sócio-histórica. São Paulo: Cortez, 2003.

OZELLA, S.; AGUIAR, W. M. J. Desmistificando a concepção de adolescência. Cadernos de Pesquisa, v. 38, n. 133, p. 97-125, jan/abr. 2008. Disponível em: <http://www.scielo.br/pdf/cp/v38n133/a05v38n133.pdf>. Acesso em: 20 mar. 2010.

PAIS, J. M. Grupos e afiliações sociais. Revista Teias, Jovens, territórios e práticas educativas, v. 12, n. 26, p. 247-286, set/dez. 2011. Disponível em: <http://www.periodicos.proped.pro.br/index.php/revistateias/article/view/986/757>. Acesso em: 20 abr. 2016.

SILVA, A. R.; MENEZES, J. A. Os significados do uso de álcool entre jovens quilombolas. Revista Latinoamericana de Ciencias Sociales, Niñez y Juventud, v. 14, n. 1, p. 493-504. Disponível em: < http://revistalatinoamericanaumanizales.cinde.org.co/wpcontent/uploads/2016/02/Vol14n1_a33.pdf>. Acesso em: 22 abr. 2016.

TUBINO, M. J. G. Dimensões sociais do esporte. São Paulo: Cortez; Autores Associados, 1992.

WALLON, H. A Psicologia da consciência. In: Do ato ao pensamento: ensaio de psicologia comparada. Petrópolis: Vozes, 1942-2008. 